\title{
FESTIVAL DE INVERNO DA UFPR: APROXIMAÇÕES LÚDICO-PEDAGÓGICAS
}

\author{
Simone RechiA* \\ Felipe Sobczynski Gonçalves** \\ RODRIGO DE FranÇA***
}

\section{RESUMO}

O presente texto visa descrever os caminhos metodológicos do projeto intitulado "Tempo de Brincar na Praça", desenvolvido em Antonina, no $15^{\circ}$ Festival de Inverno da Universidade Federal do Paraná, em 2005. Essa ação atendeu a professores da Rede Municipal de Ensino e a aproximadamente 300 crianças por dia na faixa etária de 6 a 14 anos. Coordenada por professores do Departamento de Educação Física, auxiliados por bolsistas do CEPELS/UFPR, essa intervenção se consolidou enquanto projeto de extensão, com ações práticas, no âmbito do lazer-educação. Considerando o lazer como cultura - compreendida no seu sentido mais amplo - vivenciada (praticada ou fruída) no tempo conquistado, alguns conteúdos da cultura corporal foram desenvolvidos, ampliados e transformados.

PALAVRAS-CHAVE: educação - lazer - cultura

\section{INTRODUÇÃO}

$\mathrm{O}$ Festival de Inverno da Universidade Federal do Paraná (UFPR) é um programa de extensão permanente, criado em 1991 pela PróReitoria de Extensão e Cultura e desenvolvido na cidade de Antonina, no Paraná. O festival agrega, além das atividades culturais, uma série de ações extensionistas de saúde, educação, inclusão social e geração de renda. Segundo o Reitor Carlos Augusto Moreira Júnior, ao levar o que a UFPR tem de melhor a essa cidade, a universidade realiza o verdadeiro sentido da educação e do aprendizado - a troca entre saber popular e saber acadêmico e a possibilidade da vivência do mundo concreto pelos alunos, técnicos e professores.

\footnotetext{
* Professora doutora em Educação Física da Universidade Federal do Paraná.

** Especialista em Educação Física da Universidade Federal do Paraná.

*** Mestrando em Educação Física pela Universidade Federal do Paraná.
} 
Nesse contexto, a UFPR realizou, no período de 9 a 17 de julho de 2005 , a $15^{\text {a }}$ edição do evento, com atividades voltadas principalmente à comunidade antoninense, onde foram ofertadas várias oficinas de aprimoramento, educação e arte, educação especial, exposições, ciclo de palestras, espetáculos, entre outras atividades.

A área de Educação Física da UFPR participou do $15^{\circ}$ Festival através de um projeto chamado "Festival de Inverno da UFPR -2005: tempo de pensar a escola e de brincar na praça". O festival teve como caminho metodológico a articulação simultânea entre uma oficina, cujo objetivo foi a formação continuada para professores, intitulada "Corpo brincante", e o desenvolvimento de vivências lúdicas, denominadas de "Espaço diversão", para alunos da Rede Municipal de Ensino na principal praça da cidade.

Essa ação atendeu a 20 professores que atuam nas escolas da cidade e a, aproximadamente, 300 crianças/dia na faixa etária de 6 a 14 anos. A proposta foi desenvolvida pelo Centro de Educação Física e Desportos (CED), Departamento de Educação Física (DEF) e Centro de Pesquisa em Esporte, Lazer e Sociedade (CEPELS). ${ }^{1}$

Materializamos na prática ${ }^{2}$ (com os escolares e moradores da região periférica da cidade) os conteúdos discutidos na "práxis" com os professores na oficina. ${ }^{3}$ Esta intervenção se consolidou enquanto projeto de extensão, com ações voltadas para o âmbito do lazer-educação.

Para tanto, partimos da compreensão do lazer como prática lúdica, crítica, construtiva e consciente. Bramante (1998, p. 9) complementa essa concepção, ressaltando que o lazer se traduz por uma dimensão privilegiada da expressão humana, e sua vivência também está "relacionada diretamente às oportunidades de acesso aos bens culturais, os quais são determinados, via de regra, por fatores sócio-político-econômicos e influenciados por fatores ambientais". Dessa forma, buscamos enfocar o lazer como cultura - compreendida no seu sentido mais amplo - vivenciada (praticada ou fruída) no tempo conquistado.

A vivência do lazer, portanto, exige a conscientização de que temos direito ao acesso a bens culturais. Para Freire (1980, p. 26), "a conscientização não pode existir fora da práxis, ou melhor, sem o ato de ação-reflexão. Essa unidade dialética constitui, de maneira permanente, o modo de ser e de transformar o mundo que caracteriza os homens".

Nossa principal intenção foi não apresentar simplesmente propostas prontas, mas provocar a auto-reflexão sobre as práticas dos edu- 
cadores, para estimular a elaboração própria, de forma fundamentada, do seu fazer pedagógico na escola. Portanto, para que as vivências lúdicas se efetivem no processo educacional faz-se necessário que alunos e professores conscientizem-se de que devem assumir o papel de sujeitos que fazem e refazem suas próprias experiências.

Mascarenhas (2004) adverte que para elaborar um programa de lazer é necessário mais que a simples indicação de algumas atividades, sejam elas estimulantes ou divertidas. Nas entrelinhas de um planejamento, fazem-se presentes: visão de homem, concepção de mundo e projeto histórico de sociedade. Nesta perspectiva, conteúdos como jogo, esporte, dança, luta, teatro, música, capoeira, prática circense e outros, foram desenvolvidos, ampliados e transformados, tanto pelas crianças quanto pelos educadores, por meio de um processo dinâmico de interação entre dinâmica do tempo/espaço do lazer e processo educacional.

Acreditamos que esta ação pôde contribuir para a formação um pouco mais ampliada no ambiente escolar, ao oportunizar vivências corporais lúdicas, criadoras e comunicativas, tanto para professores como para alunos, pois o ensino tradicional, como todos sabemos, tenta, ainda (com freqüente êxito), domesticar o potencial criativo e os sonhos das pessoas, por meio da disciplinarização dos corpos.

E, nesse caso, cabe lembrar Sant'Anna (2002, p. 48), ao salientar que as estratégias de controle nas mais diversas instituições são "ambiciosas, fluidas, discretas e sutis: elas pretendem constituir os corpos em todos os momentos e espaços; não apenas para torná-los dóceis e úteis no trabalho, mas, também insaciáveis no consumo de prazeres".

Assim, admitir a importância do lazer na vida moderna significa para Marcellino (1987, p. 41), considerá-lo como um

tempo privilegiado para a vivência de valores que contribuam para mudanças na ordem moral e cultural. Mudanças necessárias para a implantação de uma nova ordem social [...]. Em outras palavras: só tem sentido falar em aspectos educativos do lazer, ao considerá-lo como um dos campos possíveis da contra-hegemonia.

Portanto, a proposta, além de problematizar e sistematizar atividades culturais no tempo/espaço de lazer das crianças no período de férias, teve como função primordial proporcionar aos professores da 
Rede Municipal de Ensino de Antonina um ambiente propício para reflexão. Além disso, abre oportunidade para uma análise crítica que se contraponha à visão das práticas lúdicas como instrumento de dominação no âmbito escolar.

Para tanto, sugerimos atividades que potencializassem a criatividade e a sensibilidade dos educadores, para que descobrissem novas possibilidades de intervenção pedagógica, usando como auxílio as experiências lúdicas e tendo como pano de fundo questionamentos como: Qual o significado dessas intervenções? Que conteúdos podem ser tratados? e, quais as estratégias de intervenção?

Vale ressaltar que o projeto adotou a concepção de cultura, discutido por Marcellino (1998, p. 37), o qual aponta que esta "deve ser entendida em sentido amplo, ou seja, num conjunto de modos de fazer, ser, interagir e representar que, produzidos socialmente, envolvem simbolização e, por sua vez, definem o modo pelo qual a vida social se desenvolve".

Portanto, se compartilhamos da idéia de que a educação é um processo cultural no qual estamos inseridos cotidianamente, temos a certeza de que somos educados por tudo que nos rodeia, desde a educação sistemática, efetivada na escola, até a assistemática, que compreende os vários processos de transmissão cultural, englobando, dessa forma, toda relação pedagógica, inclusive a que se verifica no tempo/ espaço de lazer. Assim, as experiências do âmbito do lazer no espaço público de uma cidade no tempo de férias podem também contribuir para o processo educacional de maneira ampla.

Na próxima seção, em uma exposição mais detalhada da proposta, descreveremos as estratégias didático-pedagógicas da oficina "Corpo brincante" e da praça de lazer, intitulada "Espaço diversão".

\section{A OFICINA: "CORPO BRINCANTE"}

O desafio e o avanço atual para os educadores de certa forma estão situados na urgência da re-leitura das diversas manifestações lúdicas. Desafio porque coloca a necessidade de romper, na escola, a concepção da brincadeira como preparo e não apenas como ferramenta. Avanço porque uma vez consciente desse valor, o educador passa a visualizar a importância de colocar a brincadeira de volta na escola e 
de utilizá-la como conteúdo curricular, descobrindo nela uma fonte de desenvolvimento e aprendizagem.

$\mathrm{Na}$ verdade, tomar consciência desse processo requer, mudanças em cada um de nós. Essas mudanças, porém, não acontecem de forma automática: são necessárias vivências pessoais para ressignificar e incorporar o espírito lúdico em nossas vidas.

A oficina "Corpo brincante" partiu da idéia de que o primeiro passo para poder trabalhar nessa perspectiva com as crianças, é o professor re-aprender a brincar com o seu corpo, com o espaço e os objetos, com a sua imaginação, criatividade e inteligência, não abrindo mão da intuição, das palavras, do conhecimento.

Percebendo principalmente a importância das redes de sociabilidade nesse processo e tendo em vista tais intenções, destacamos que o enfoque da nossa ação didático-pedagógica teve também, como objetivo, conscientizar os educadores de que conceber o lazer como prática social e pedagógica

é ver no conjunto de suas atividades a possibilidade de produção e construção de um conhecimento que, em seu caráter crítico e emancipador, guarda uma estreita relação com o real, extraindo dados e elementos, desvelando suas origens, identificando as contradições e localizando o lugar que ocupa na totalidade de um determinado contexto (MASCARENHAS, 2004, p. 37).

\section{OBJETIVOS ESPECÍFICOS DA OFICINA}

A oficina teve como tema gerador, a dimensão lúdica e todos os seus desdobramentos no processo do desenvolvimento infantil. Procurou-se problematizar a importância, para o processo educacional, das experiências lúdicas através da re-leitura dos jogos populares, salientando as possíveis articulações entre brincadeira, práticas sociais, identidade cultural, meio ambiente, e outras possibilidades.

Para Mascarenhas (2004, p. 37), o tema gerador pode ser considerado como entrada para a realidade de um grupo:

ele servirá como ponto de sustentação do método em questão, configurar-se-á como objeto de reflexão e guardará seu aspecto gerador de 
interesse, permitindo a apropriação consciente e transformadora da realidade inerente ao contexto do qual emerge e se inscreve.

Buscamos dessa forma, estimular reflexões, privilegiando situações relativas à educação em geral e as práticas corporais lúdicas em particular, a partir dos conceitos de cultura e cultura popular.

Outro enfoque proposto, foi o de analisar as relações que podem se estabelecer entre lazer, educação e cultura corporal no processo de escolarização, problematizando as questões pedagógicas vivenciadas nos espaços públicos/privados e na escola, apontando dificuldades, possibilidades, avanços e retrocessos. Para tanto, buscamos a articulação entre a especificidade do tema e o todo da escola, penetrando na realidade do grupo, observando seus códigos, seus valores e a identidade da cultura local.

\section{A PRAÇA DE LAZER: "ESPAÇO DIVERSÃO"}

Este espaço ficou situado na praça principal de Antonina, chamada Praça Cel. Macedo. As atividades por nós sugeridas tiveram como meta (re)significar as brincadeiras e os brinquedos simples e comuns de antigamente. $\mathrm{O}$ objetivo foi divulgar as brincadeiras e jogos populares para que, a partir dessas experiências, tais práticas voltassem a fazer parte do cotidiano das crianças e adolescentes nos âmbitos escolar e não-escolar da cidade.

Partimos da idéia de que para compreender a noção das brincadeiras tradicionais devemos situá-las dentro de um contexto mais amplo de cultura, da qual faz parte o folclore, e, mais especificamente, a cultura infantil.

Assim, para Friedmann (1996, p. 40), os fatos folclóricos são "as maneiras de pensar, sentir e agir de um povo, preservadas pela tradição popular e pela imitação". Sob essa perspectiva, entendemos a cultura popular como valores considerados sobrevivências, os quais são acessíveis a um grande número de indivíduos porque sua transmissão se faz por meio de processos informais e pelo intercâmbio cotidiano.

Para planejar as atividades, fizemos um levantamento das brincadeiras tradicionais da região e escolhemos aquelas transmitidas de forma expressiva de uma geração a outra, fora das instituições oficiais, na rua, nos parques, nas praças, etc., e incorporadas pelas crianças de 
forma espontânea. Essas brincadeiras constituem-se parte do patrimônio lúdico-cultural infantil do Paraná e traduzem valores, costumes, formas de pensamento e ensinamentos.

Em outras palavras, ao propormos as atividades na praça, priorizamos as características das brincadeiras populares, pois, de acordo com Brandão (1982, p. 42), devemos considerar que o folclore é "popular, anônimo, coletivizado, tradicional e persistente, funcional à sua cultura e passível de modificações. Esses indicadores devem ser respeitados nos contextos sociais onde existe e se reproduz a criação popular". Dessa forma, compreendemos que o folclore infantil é cultural e politicamente ativo, porque decodifica a identidade e reproduz os símbolos que consagram um modo de vida.

A aceitação coletiva, anônima ou não, e essencialmente popular, contribuiu para a dinâmica das atividades da praça, entendendo que a comunidade faz, refaz, inova, recupera, retoma o antigo, incorpora o velho no novo e transforma um como poder do outro.

As manifestações das brincadeiras populares na praça buscaram elo entre presente e passado, facilitando a preservação de valores sociais, como também, priorizaram a manifestação da riqueza da cultura corporal das crianças, identificando suas potencialidades corporais, motoras, sensoriais, intelectuais, emocionais e sociais.

Segundo Friedmann (1996, p. 40), através da Cultura Folclórica Infantil, as crianças:

alargam suas relações de sociabilidade; aprendem de modo mais acessível as vantagens e o significado das atividades organizadas grupalmente; experimentam os diferentes papéis associados às relações de subordinação e de dominação entre pessoas da mesma posição social; identificam-se com os interesses ou com os valores cujas polarizações de lealdade transcendem o âmbito da família; adquirem uma experiência social de completa significação para o desenvolvimento de sua personalidade.

Dessa forma, durante sete dias foram desenvolvidas diversas brincadeiras. Adultos e crianças puderam se divertir juntos em atividades como futebol de botão e de prego, bafo com figurinhas, elástico, amarelinha, pula-corda, bolinha de gude, perna-de-pau, brincadeiras de roda; jogos gigantes de tabuleiro, como ludo, dama, jogo da velha; jo- 
gos de quebra-cabeça gigante com lona, blocos de construção, esqui de grama (chinelão), trilha, minhocões, entre outras.

Também fizeram parte das atividades, desafios de coragem como a "falsa baiana", alguns elementos das Artes Circenses como tecido, trapézio e acrobacias de solo (além da confecção e manipulação de bolinhas de malabares). Contemplamos apresentações de artistas que trabalham com a arte do palhaço. Oportunizamos, além disso, a capoeira (contextualizando sua origem e os fundamentos básicos), a dança popular e folclórica (vivenciada de forma espontânea no coreto da praça), o contador de histórias, práticas de educação ambiental e outras atividades. Com essa intervenção, buscamos, através das atividades lúdicas, oportunizar um "(re)encontro" com a cultura infantil da comunidade antoninense.

Nossa ação pretendeu oportunizar experiências no âmbito do lazer, da educação e da cultura que contribuíssem para uma formação mais humana através de atividades corporais lúdicas, criadoras e comunicativas, de educadores, crianças e adolescentes.

Assim, a proposta buscou sensibilizar as pessoas, usando, além do recurso da música, da dramaturgia, do canto, da literatura, da dança, da ginástica, do esporte e demais manifestações da cultura corporal, práticas que visassem à releitura das brincadeiras populares, contribuindo para que a comunidade assumisse um papel de reflexão crítica diante da problemática referente à preservação da memória, garantindo, dessa forma, a discussão acerca do significado da convivência coletiva, enquanto espaço de construção e afirmação de identidades.

\section{QUANTO AO PLANEJAMENTO}

Nossa concepção, tanto da Oficina quanto da Praça, permite-nos dizer que todos os envolvidos - bolsistas, professores e crianças - se sentiram sujeitos do processo de construção/elaboração do desenvolvimento das atividades, compartilhando responsabilidades e possíveis avanços que aconteceram no momento da realização do projeto. A estratégia metodológica priorizou a construção coletiva de procedimentos, desde a seleção das atividades até a efetivação total da proposta.

Acreditamos que as propostas mais usuais de intervenção em eventos dessa natureza ainda se encontram dentro da perspectiva do lazer funcional. Buscando romper com esse paradigma, oportunizamos uma ação diferenciada para todos os envolvidos no processo para que 
pudessem discutir, propor e planejar subsídios teórico-metodológicos diferenciados.

Sendo assim, nosso objetivo foi promover um planejamento dentro da perspectiva crítica do lazer-educação, que contemplasse uma prática do lazer de forma criativa, lúdica e transformadora, mas também uma melhor capacitação/formação dos estagiários e dos educadores envolvidos, possibilitando a reflexão de suas próprias ações e a oportunidade para vislumbrarem novas formas de intervenção.

\section{ALGUMAS CONSIDERAÇÕES FINAIS}

Vivemos em uma sociedade com características pós-industriais, que carrega consigo avanços e retrocessos, os quais denunciam diversas contradições advindas do maior alcance tecnológico e conseqüentemente de todos os seus desdobramentos. Em função disso, várias transformações sociais são percebidas, entre as quais pode-se identificar uma sensível mudança nos estilos de vida, envolvendo especialmente o contexto das práticas corporais. Embora saibamos de toda a problemática que envolve este assunto, gostaríamos de salientar a limitação do espaço/tempo de lazer no meio urbano para a fruição da cultura corporal. Uma das causas dessa limitação situa-se na transformação das casas e seus enormes jardins em grandes condomínios, conjuntos habitacionais, avenidas, centros empresariais, indústrias, entre outros empreendimentos arquitetônicos.

Essa nova configuração das cidades gerou para crianças e jovens uma drástica redução dos espaços. Houve um recuo em relação ao espaço do brincar, que tradicionalmente se dava nos quintais ou nas ruas. Hoje, os brinquedos industrializados, geralmente eletrônicos (enaltecidos pela mídia) acabam preferidos das crianças e dos pais, em espaços limitados e predeterminados para o lazer, reflexo da violência urbana. São jogos que induzem a estática do corpo e com poucas chances de contato mais próximo com a Natureza.

Dessa forma, a falta de espaço para as vivências lúdicas de crianças e adolescentes é um problema essencial das sociedades contemporâneas, em que o uso de espaços e equipamentos para o jogo ${ }^{4} \mathrm{em}$ tempos e ambientes diferenciados (escolas, áreas verdes e locais públicos) deve ser analisado em sintonia com as necessidades e motivações das populações nos meios urbanos. Para tanto, faz-se necessário identificar 
o cotidiano das pessoas, considerando a multiplicidade de estilos de vida (espaços livres, tempo disponível, dinâmicas sociais e familiares, condição socioeconômica, etc.), visualizando tanto as questões referentes à modernização de espaços e equipamentos lúdicos, quanto as relativas à acessibilidade, segurança, manutenção, supervisão e estratégias de intervenção.

Diante desse contexto de "corpos imobilizados" pela dinâmica do espaço, torna-se imprescindível colocar o seguinte questionamento: Quais os espaços privilegiados no meio urbano que oferecem mais potencialidades para as vivências do jogo? O ambiente escolar pode efetivamente se afirmar como uma das alternativas? A escola está atenta a essa problemática?

Assim, a partir dessas questões norteadoras, selecionamos alguns conteúdos que foram trabalhados nesse projeto de extensão, buscando analisar os espaços destinados às práticas corporais lúdicas, na tentativa de focalizar como essas práticas são vivenciadas nas escolas e conseqüentemente nos espaços de lazer da cidade de Antonina.

Através destes relatos preliminares, pudemos perceber que as experiências do brincar e do jogar no ambiente escolar e não escolar estão sujeitas à arquitetura dos espaços de lazer das cidades e às oportunidades nas escolas, mas não são totalmente limitadas por estes fatores, pois o desejo de se divertir das crianças supera tais dificuldades, revelando que as práticas lúdicas se dão por intermédio de uma relação de tensão permanente entre adultos e crianças.

Neste sentido, esperamos sensibilizar educadores da Rede Pública de Ensino e gestores sobre a importância do planejamento compartilhado dos espaços de lazer das cidades e do reconhecimento da dinâmica lúdica que se desenvolve em ambientes educacionais.

Portanto, nosso interesse ao descrever o projeto "Festival de Inverno da UFPR -2005: tempo de pensar a escola e de brincar na praça", é contribuir para o debate sobre os espaços e as experiências do brincar e do jogar nas cidades, na perspectiva do lazer/educação, apontando e desvelando idéias para a realização de ações conjuntas entre a formação continuada de professores e a dinâmica de eventos de lazer nas cidades.

Acreditamos que este relato, sustentado em um projeto que abrange e contempla o tripé ensino/pesquisa/extensão, poderá trazer importantes subsídios para educadores e gestores, já que possibilita a compreensão um pouco mais aprofundada de algumas formas de inter- 
venção da Universidade, demonstrando como acontece a "negociação" entre o jogo do espaço e o espaço do jogo no ambiente escolar e não escolar em uma cidade.

\title{
Ufpr's winter festival: Playful pedagogical approaches
}

\begin{abstract}
The present text intends to describe the methodologic paths of the Project named "Tempo de Brincar na Praça", ("Time to Play in the Square"), developed in the city of Antonina during the 15th Winter Festival of the Universidade Federal do Paraná, Brazil, in 2005. This project reached local public school teachers and approximately 300 children aged 6-14 on a daily basis. Coordinated by teachers from the Department of Physical Education and aided by CEPEL/UFPR scholarship students, this activity was consolidated as a university extension project with practical actions in the range of leisure and education. Considering leisure as a form of culture - taken in its broadest sense - to be lived (practiced or enjoyed) in a hard-won time, some contents of body culture have been developed, broadened, and transformed.
\end{abstract}

KEYWORDS: Education - Leisure - Culture

Festival de inverno de la UFPR: aproximaciones lúdico-pedagógicas

\section{RESUMEN}

El presente texto visa describir los caminos metodológicos del proyecto intitulado “Tiempo de Jugar en la Plaza", desarrollado en Antonina, en el $15^{\circ}$ Festival de Invierno de la Universidad Federal de Paraná, en 2005. Esa acción atendió a profesores de la Red Municipal de Enseñanza y a aproximadamente 300 niños por dia en faja etaria de 6 a 14 años. Coordinada por profesores del Departamento de Educación Física, auxiliados por bolsistas del CEPELS/UFPR, esa intervención se consolidó como proyecto de extensión, con acciones prácticas, en ámbito del ocio-educación. Considerando el ocio como cultura - comprendida en su sentido más amplio - vivenciada (practicada o disfrutada) en tiempo conquistado, algunos contenidos de la cultura corporal fueron desarrollados, ampliados y transformados.

PALABRAS-CLAVE: Educación - Ocio - Cultura

\section{NOTAS}

1 Órgãos desta Universidade.

2 Essa atividade aconteceu das 14 às 17 horas, durante uma semana, na praça principal da cidade. As crianças eram transportadas das regiões mais afastadas até a praça todos os dias.

3 A oficina "Corpo brincante", realizou-se das 9 às 12 horas, durante a mesma semana, com o objetivo de desenvolver com as professo- 
ras as mesmas atividades que as crianças vivenciavam à tarde na praça.

4 Entende-se por jogo, o processo de dar liberdade para as crianças e jovens de exprimir a sua motivação intrínseca e a necessidade de explorar as suas potencialidades físicas e sociais, sem constrangimentos (investigar, testar e afirmar experiências e possibilidades de ação).

\section{REFERÊNCIAS}

BRAMANTE, C. A. Lazer: concepções e significados. Licere, Belo Horizonte, v. 1, n. 1, set. 1998.

BRANDÃO, C. R. O que é folclore. 7. ed. São Paulo: Brasiliense, 1982.

FREIRE, P. Conscientização: teoria e prática da libertação. 3. ed. São Paulo: Morais, 1980.

FRIEDMANN, A. Brincar: crescer e aprender - o resgate do jogo infantil. São Paulo: Moderna, 1996.

MARCELLINO, N. Lazer e educação. Campinas: Papirus, 1987. . Lazer: concepções e significados. Licere, Belo Horizonte, v. 1, n. 1, set. 1998 .

MASCARENHAS, F. Lazer como prática da liberdade: uma proposta educativa para a juventude. 2. ed. Goiânia: UFG, 2004.

SANT'ANNA, B. D. Entre a serpente e a toupeira: transitando pelas idéias de Foucault e Deleuze. In: BRUHNS, H. T. (Org.). Lazer e ciências sociais: diálogos pertinentes. São Paulo: Chronos, 2002. (Coleção Lazer, esporte e sociedade).

Recebido: 10 de outubro de 2005 Aprovado 10 de dezembro de 2005 
Endereço para correspondência:

Universidade Federal do Paraná

Departamento de Educação Física

Rua Coração de Maria, 92 / BR 116 Km 95

Jardim Botânico - Curitiba - Paraná

CEP 80215-370

Tel. (41) 360-4328/ Fax (41) 360-4336

E-mail: simone@ufpr.br

rodrigofranca@yahoo.com.br

fe.lipinho@bol.com.br 
